\title{
Single-dose pharmacokinetics of temocillin in plasma and soft tissues of healthy volunteers after intravenous and subcutaneous administration: a randomized crossover microdialysis trial
}

\author{
Peter Matzneller $\mathbb{D}^{1}$, Perrin Ngougni Pokem ${ }^{2}$, Arnaud Capron ${ }^{3}$, Edith Lackner ${ }^{1}$, Beatrix Wulkersdorfer ${ }^{1}$, \\ Alina Nussbaumer-Pröll ${ }^{4}$, Zoe Österreicher ${ }^{4}$, Michael Duchek ${ }^{1}$, Sebastien Van de Velde $\mathbb{D}^{5}{ }^{5}$, Pierre E. Wallemacq ${ }^{3}$, \\ Johan W. Mouton ${ }^{6}$, Françoise Van Bambeke $\mathbb{D}^{2}$ and Markus Zeitlinger ${ }^{1 *}$ \\ ${ }^{1}$ Department of Clinical Pharmacology, Medical University of Vienna, Austria; ${ }^{2}$ Pharmacologie cellulaire et moléculaire, Université \\ catholique de Louvain, Brussels, Belgium; ${ }^{3}$ Clinical Chemistry Department, Cliniques Universitaires St. Luc, Université catholique de \\ Louvain, Brussels, Belgium; ${ }^{4}$ Department of Medicine 1, Division of Infectious Diseases and Tropical Medicine, Medical University of \\ Vienna, Vienna, Austria; ${ }^{5}$ EUMEDICA S.A. Manage, Belgium; ${ }^{6}$ Department of Medical Microbiology and Infectious Diseases, Erasmus MC, \\ Rotterdam, The Netherlands
}

*Corresponding author. E-mail: markus.zeitlinger@meduniwien.ac.at

Received 4 September 2019; returned 21 November 2019; revised 30 March 2020; accepted 7 April 2020

\begin{abstract}
Background: The antibiotic temocillin has recently been rediscovered as a promising therapeutic option against MDR Gram-negative bacteria. However, some aspects of the pharmacokinetic (PK) profile of the drug are still to be elucidated: subcutaneous administration of temocillin might be of interest as an alternative to the intravenous route in selected patients. Similarly, information on the penetration of temocillin into human soft tissues is lacking.
\end{abstract}

Objectives: To investigate the feasibility and plasma PK of subcutaneous dosing as well as soft tissue PK of temocillin after intravenous administration to healthy volunteers.

\begin{abstract}
Methods: Eight healthy volunteers received $2 \mathrm{~g}$ of temocillin both as intravenous and subcutaneous infusion in a randomized two-period crossover study. Concentration-time profiles of total temocillin in plasma (after both routes) and of unbound temocillin in plasma, muscle and subcutis (only after intravenous dosing) were determined up to $12 \mathrm{~h}$ post-dose.
\end{abstract}

\begin{abstract}
Results: Subcutaneous dosing caused some infusion site discomfort but resulted in sustained drug concentrations over time with only slightly decreased overall exposure compared with intravenous dosing. Plasma protein binding of temocillin showed concentration-dependent behaviour and was higher than previously reported. Still, unbound drug concentrations in muscle and subcutis determined by microdialysis markedly exceeded those in plasma, suggesting good tissue penetration of temocillin.

Conclusions: The subcutaneous administration of temocillin is a valid and feasible alternative to intravenous dosing. With the description of plasma protein binding and soft tissue PK of temocillin in healthy volunteers, this study provides important information that adds to the ongoing characterization of the PK profile of temocillin and might serve as input for PK/PD considerations.
\end{abstract}

\section{Introduction}

In the face of the increasing prevalence of Gram-negative multidrug resistance, the penicillin antibiotic temocillin has recently been re-evaluated as a therapeutic option.

Temocillin's most prominent feature is its resilience against all classical and extended-spectrum $\beta$-lactamases (ESBLs) and against AmpC enzymes. While the narrow spectrum of activity (which does not include Gram-positive organisms, anaerobes and Pseudomonas aeruginosa) may have been seen as a drawback, its limited previous use preserved its activity over several decades. Thus, in settings where infections with temocillin-non-susceptible pathogens are unlikely or covered by concomitant therapy, it may well be considered as a valid alternative to carbapenems. ${ }^{1}$

Temocillin is currently approved for intravenous and intramuscular use in Belgium, UK, Luxembourg, France and Iran. However, we are increasingly facing older patients and it is acknowledged that oral, intravenous and/or intramuscular administration can be problematic in the palliative and/or geriatric setting. Remarkably, antimicrobial drugs are among the most frequent prescriptions in 
these patients. ${ }^{2}$ In this context, the subcutaneous route has proven to be a practical and increasingly important alternative way of administering drug therapy. ${ }^{3}$

Establishing the subcutaneous route as an equivalent mode of administration would allow minimization of nursing care in situations where oral, intravenous or intramuscular dosing is difficult to achieve. Subcutaneous dosing has already been described for a number of antimicrobial drugs, with little or no difference in overall exposure and only minor local tolerability issues compared with intravenous infusion. ${ }^{4-10}$ For temocillin, the available data regarding subcutaneous administration are strictly limited to animal studies. ${ }^{7,11-13}$ Still, the above-mentioned reasons explain why the clinical interest in safety and pharmacokinetics (PK) of temocillin following subcutaneous administration to human patients is high.

Therefore, this study set out to investigate the feasibility and plasma PK of a single subcutaneous infusion of temocillin in a healthy volunteer population.

In addition, this study sought to elucidate a second aspect that is crucial for an optimized use of temocillin. Among the current and future indications of the drug are wound infections and soft tissue infections. ${ }^{11}$ However, to date, the PK of temocillin in soft tissues has not been investigated.

It is well acknowledged (and recommended by regulatory bodies) that the PK of a compound should be assessed at the site where it is supposed to exert its pharmacological action. ${ }^{14}$ For most anti-infective agents, this is the extracellular (interstitial) space of the tissue/compartment of interest. ${ }^{15}$ Information on target site PK is highly important as a basis for pharmacokinetic/pharmacodynamic (PK/PD) simulations and may also inform the definition of appropriate breakpoints.

According to these premises, this study was designed to describe the PK of temocillin in plasma, muscle and subcutis of healthy volunteers following a single intravenous infusion.

\section{Patients and methods}

\section{Materials}

Temocillin (Negaban ${ }^{\circledR} 2 \mathrm{~g}$ powder for solution for injection/infusion) as well as temocillin pure substance was kindly provided by Eumedica S.A., Belgium. Lidocaine (Xylocaine ${ }^{\circledR} 1 \%$ vials, AstraZeneca) was purchased from the Hospital Pharmacy of the Vienna General Hospital. Physiological 0.9\% saline solution was purchased from Medica Medicare, Kufstein, Austria. All microdialysis equipment was purchased from MDialysis, Stockholm, Sweden.

\section{Pharmacokinetic study}

This prospective, open-label, randomized, two-period, two-way crossover PK study was conducted at the Department of Clinical Pharmacology at the Medical University of Vienna, Austria, in accordance with the current ICHGCP guidelines and the current version of the Declaration of Helsinki. The study was registered under the EudraCT number 2015-003457-18 and was approved by the Ethics Committee of the Medical University of Vienna (study code 1737/2015) and the Austrian Agency for Health and Food Safety. Before inclusion, all study subjects gave oral and written informed consent to study participation. All subjects underwent a screening visit including documentation of medical history, physical examination, blood sampling for haematology, clinical chemistry, virology and coagulation tests, urine dipstick analysis as well as ECG recording and non-invasive arterial blood pressure measurement. Key inclusion criteria were: male, age 18-55 years, BMI $20-30 \mathrm{~kg} / \mathrm{m}^{2}$, no regular medication and written informed consent. Key exclusion criteria were known allergy against the study drugs and clinically relevant abnormal physical or laboratory findings. During study visits, subjects were under constant direct observation of a study physician or an experienced nurse and were regularly questioned about the occurrence of adverse events. Upon study completion, all subjects underwent a final examination that was identical to the screening visit except for viral serology and urinalysis.

Enrolled study subjects had to undergo two study periods separated by a washout phase of at least 3 days in a sequence determined by randomization.

Depending on the study period, subjects received a single dose of $2 \mathrm{~g}$ of temocillin either as intravenous infusion over 40 min or as subcutaneous infusion into one thigh over $20 \mathrm{~min}$. For intravenous infusion, $2 \mathrm{~g}$ of temocillin was dissolved in $10 \mathrm{~mL}$ water for injection and then further diluted in the same medium to give a final infusion volume of approximately $110 \mathrm{~mL}$, which was administered by means of a Braun ${ }^{\circledR}$ infusion pump. For subcutaneous administration, $2 \mathrm{~g}$ of temocillin was dissolved in equal parts in water for injection and $1 \%$ lidocaine to give a total infusion volume of approximately $4.3 \mathrm{~mL}$, which was transferred in a syringe and administered by means of a WPI ${ }^{\circledR}$ precision pump.

At each study visit including screening, study subjects were questioned about the occurrence of adverse events. All events were documented in full detail and graded for severity as well as for causal relationship with the study drug. All adverse events were followed up until resolution.

In both study periods, total temocillin concentrations in plasma were measured at baseline (within $10 \mathrm{~min}$ prior to dosing) as well as $40 \mathrm{~min}$ and $1,2,3,4,5,6,7,8,10$ and $12 \mathrm{~h}$ after study drug administration. Venous blood samples collected into Vacuette ${ }^{\circledR}$ lithium-heparin tubes from an indwelling venous line in the contralateral arm to the one used for infusion were placed on ice immediately after collection and subsequently centrifuged ( $2000 \mathrm{~g}, 10 \mathrm{~min}, 4^{\circ} \mathrm{C}$ ). Resulting plasma was divided into two aliquots and snap frozen at $-20^{\circ} \mathrm{C}$ within 60 min of collection.

In addition, only after intravenous administration, unbound temocillin concentrations were directly measured in muscle and subcutis of healthy volunteers by means of microdialysis over defined 60 min sampling intervals $(0-1,1-2,2-3,3-4,4-5,5-6,6-7,7-8,8-9$ and $9-10 h$ after dosing).

Principles and detailed methodology of microdialysis have been described before. ${ }^{16,17}$ In this study, two 63 Microdialysis Catheters ( $\mu$ Dialysis, Stockholm, Sweden) with a membrane length of $10 \mathrm{~mm}$ and a molecular weight cut-off of $20 \mathrm{kDa}$ were inserted into muscle and subcutaneous adipose tissue of one thigh of each healthy volunteer, respectively. From insertion onwards, all probes were continuously perfused with $0.9 \%$ saline solution at a flow rate of $2 \mu \mathrm{L} / \mathrm{min}$ by means of precision pumps. The study drug was administered after an equilibration/baseline sampling period of at least $60 \mathrm{~min}$.

After completion of PK sampling, microdialysis probes were individually calibrated by retrodialysis. The principle of this method relies on the fact that the exchange process across the semi-permeable membrane is assumed to be quantitatively equal in both directions. The percentage of analyte that crosses the membrane is termed relative recovery (RR) and can be calculated as:

RR $(\%)=100$

$$
\text { - }\left(100 \times \text { analyte concentration }_{\text {out }} / \text { analyte concentration }_{\text {in }}\right)
$$

In turn, interstitial concentrations were calculated according to the following equation:

$$
\text { Interstitial concentration }=100 \times(\text { sample concentration/RR })
$$

For this purpose, probes were perfused with a known concentration of temocillin $(200 \mathrm{mg} / \mathrm{L})$ at a flow rate of $2 \mu \mathrm{L} / \mathrm{min}$. After a run-in phase of $30 \mathrm{~min}$, two retrodialysis samples (30-60 and 60-90 min, respectively) and 
one aliquot of the calibration solution were collected for each probe. After completion of calibration, microdialysis probes were removed.

All microdialysis samples were snap frozen at $-20^{\circ}$ immediately after collection. At the end of each study day, all plasma and microdialysate samples were transferred to $-80^{\circ} \mathrm{C}$, where they remained stored until analysis.

Temocillin was extracted from plasma samples by methanolic precipitation. Unbound temocillin was extracted from plasma samples by ultrafiltration (only for samples collected after intravenous infusion, Amicon filter Ultra-15 device; NMWL 30K; Merck Millipore Ltd; recovery 99.72\%$106.08 \%$ ). Microdialysate samples and ultrafiltrates were added in the same volume of methanol as plasma samples. All these samples were assayed by an HPLC-MS/MS method previously validated in serum and fully revalidated here in plasma for both total and unbound concentrations (relative bias $\leq 3.17 \%$ and $2.14 \%$; maximal relative standard deviation (RSD) values for repeatability/highest intermediate precision 3.38\%/4.25\% and $4.49 \% / 5.40 \%$; limit of quantification 1 and $0.75 \mathrm{mg} / \mathrm{L}$ for total and unbound concentrations, respectively). ${ }^{18}$ Calibration curves in physiological saline were used to quantify temocillin in microdialysates.

Pharmacokinetic parameters of total (plasma) and unbound (plasma and soft tissues) temocillin were calculated by means of noncompartmental analysis using Phoenix WinNonLin ${ }^{\circledR}$ (Certara, Princeton, NJ, USA). Peak concentration, time to peak concentration, area under the AUC curve from 0 to $12 \mathrm{~h}$ post-dose and from time 0 to infinity, half-life, apparent volume of distribution and clearance were calculated using noncompartmental analysis for total and unbound drug concentrations. For muscle and subcutis, unbound temocillin concentrations at $12 \mathrm{~h}$ post-dose were calculated assuming first-order elimination kinetics.

The fraction of the dosing interval during which free drug concentration exceeded the MIC was calculated with Phoenix WinNonLin ${ }^{\circledR}$ (Certara, Princeton, NJ, USA) based on the measured observations. Interpolation between measured data points was used to obtain the time value where the interpolated concentration crossed a defined MIC threshold. ${ }^{19}$ Previously described $\mathrm{MIC}_{90}$ values for relevant ESBL and $\mathrm{AmpC}$ producers ( 8 and $16 \mathrm{mg} / \mathrm{L}$, respectively) were used. ${ }^{20,21}$

Statistical analysis was performed using version 20 of a commercially available computer program (SPSS, IBM, Armonk, NY). The Shapiro-Wilk test was used to test for normal distribution. Normally distributed parameters are presented as mean $\pm S D$ and non-normally distributed parameters were natural log transformed. A linear mixed model (with treatment, period and sequence as fixed effects and subject ID as a random effect) was employed to compare intravenous and subcutaneous administration of temocillin as well as to exclude relevant sequence and period effects. A related-samples Wilcoxon rank sum test was used to compare non-compartmental analysis (NCA) estimates between plasma, muscle and subcutaneous compartments. Statistical significance was defined as $P<0.05$. The Bonferroni-Holm correction method was used to correct for errors related to multiple testing.

\section{Results}

Eight male healthy volunteers (mean \pm SD age and BMI, $32.9 \pm 12.1$ years and $24.4 \pm 2.9 \mathrm{~kg} / \mathrm{m}^{2}$, respectively) were enrolled. All subjects completed the study. Temocillin was well tolerated after intravenous dosing. During subcutaneous infusion, pain (two out of eight subjects), burning sensation (four subjects) and heat sensation (one subject) at the infusion site were reported, all of mild intensity and strictly limited to the time of subcutaneous infusion. Also, one case of mild, circumscript hypoaesthesia (duration 5 months) and one case of mild tenderness (duration 3 months) at the infusion site occurred after subcutaneous dosing. Both were followed up, including neurological assessment, and resolved without sequelae.

Concentration-time profiles of total and unbound temocillin in the investigated compartments after intravenous and subcutaneous dosing are shown in Figure 1. Key PK parameters of temocillin in the investigated compartments are summarized in Table 1.

\section{Concentrations in plasma}

After intravenous infusion, mean $\pm S D C_{\max }$ and $A \cup C_{0-12}$ of total temocillin were $233.5 \pm 50.2 \mathrm{mg} / \mathrm{L}$ and $959.4 \pm 185.0 \mathrm{mg} \cdot \mathrm{h} / \mathrm{L}$, respectively. Subsequently, temocillin concentrations followed a loglinear pattern, with a mean $\pm S D t_{1 / 2}$ computed from the terminal slope of $5.3 \pm 1.3 \mathrm{~h}$ (in very good agreement with the Summary of Product Characteristics, although a fully appropriate calculation of half-life might require a more extended sampling period). The mean \pm SD concentration at timepoint $12 \mathrm{~h}$ post-dose was $29.9 \pm 7.4 \mathrm{mg} / \mathrm{L}$. $V$ was roughly of the magnitude of extracellular fluid (13.0+2.7 L) and $C L$ was $1.7 \pm 0.3 \mathrm{~L} / \mathrm{h}$.

Compared with intravenous infusion, subcutaneous dosing produced a slower and less pronounced increase in the total concentration of temocillin in plasma. Plasma $C_{\max }$ of total temocillin was reached only at $4.8 \pm 2.0 \mathrm{~h}$ post-dose and was $100.0 \pm 15.5 \mathrm{mg} / \mathrm{L}$, i.e. less than half of the $C_{\max }$ observed after intravenous infusion. However, this was compensated by sustained drug levels in plasma over time. As can be seen in Figure 1, the temocillin concentration-time curve after subcutaneous infusion crossed and moved above the intravenous curve at approximately $4 \mathrm{~h}$ postdose. Afterwards, temocillin plasma concentrations of subcutaneously dosed subjects remained above those of the intravenous group for the remainder of the dosing interval. At the last observed timepoint, $12 \mathrm{~h}$ post-dose, total temocillin concentrations in the subcutaneous group were still significantly higher compared with the intravenous route $(50.3 \pm 15.3$ versus $29.9 \pm 7.4 \mathrm{mg} / \mathrm{L}$, respectively). After subcutaneous dosing $V$ was $14.5 \pm 3.2 \mathrm{~L}$.

The $\mathrm{AUC}_{0-\infty}$ of temocillin after subcutaneous administration was markedly higher $(1314.0 \pm 242.1 \mathrm{mg} \cdot \mathrm{h} / \mathrm{L})$ than $\mathrm{AUC}_{0-\infty}$ after intravenous dosing $(1197.1 \pm 276.6 \mathrm{mg} \cdot \mathrm{h} / \mathrm{L})$, resulting in a relative bioavailability of $112 \% \pm 19 \%$ (range $92.6 \%-139.6 \%$ ).

The $\mathrm{AUC}_{0-12}$ of temocillin after subcutaneous dosing amounted to $818.1+90.3 \mathrm{mg} \cdot \mathrm{h} / \mathrm{L}$, corresponding to $86.6 \% \pm 10.0 \%$ (range $70.1 \%-100.9 \%$ ) of the value after intravenous administration. No significant sequence or period effect was observed between the intravenous and subcutaneous groups.

The concentration-time profile of unbound temocillin in plasma following intravenous infusion is also depicted in Figure 1. After peaking at $34.6 \pm 11.0 \mathrm{mg} / \mathrm{L}$ [in line with a mean unbound fraction $\left(f_{u}\right)$ of $15 \%$ ], free concentrations declined quite rapidly, leading to $f_{u}$ values of $6.8 \% \pm 1.7 \%$ and $5.5 \% \pm 1.3 \%$ at 2 and $12 \mathrm{~h}$ post-dose, respectively. Overall, $f_{u}$ changed in good accordance with total concentrations (correlation coefficient $0.69, P \ll 0.01$ ), suggesting concentration-dependent protein binding. The mean $\pm S D A U C_{0-12}$ of unbound drug amounted to $67.2 \pm 13.3 \mathrm{mg} \cdot \mathrm{h} / \mathrm{L}$, corresponding to $7 \%$ of the aforementioned $\mathrm{AUC}_{0-12}$ for total temocillin.

Assuming a dosing scheme of $2 \mathrm{~g}$ of temocillin twice daily, the $\mathrm{fT}_{>\mathrm{MIC}}$ of temocillin in plasma after intravenous infusion was $18.4 \%$ for an MIC of $8 \mathrm{mg} / \mathrm{L}$ and $7.6 \%$ for an MIC of $16 \mathrm{mg} / \mathrm{L}$ (Table 2 ).

\section{Concentrations in soft tissues}

Soft tissues were investigated by microdialysis. Mean \pm SD relative recovery values determined by retrodialysis were $16.4 \%+4.5 \%$ for muscle and $9.6 \% \pm 2.5 \%$ for subcutis. 


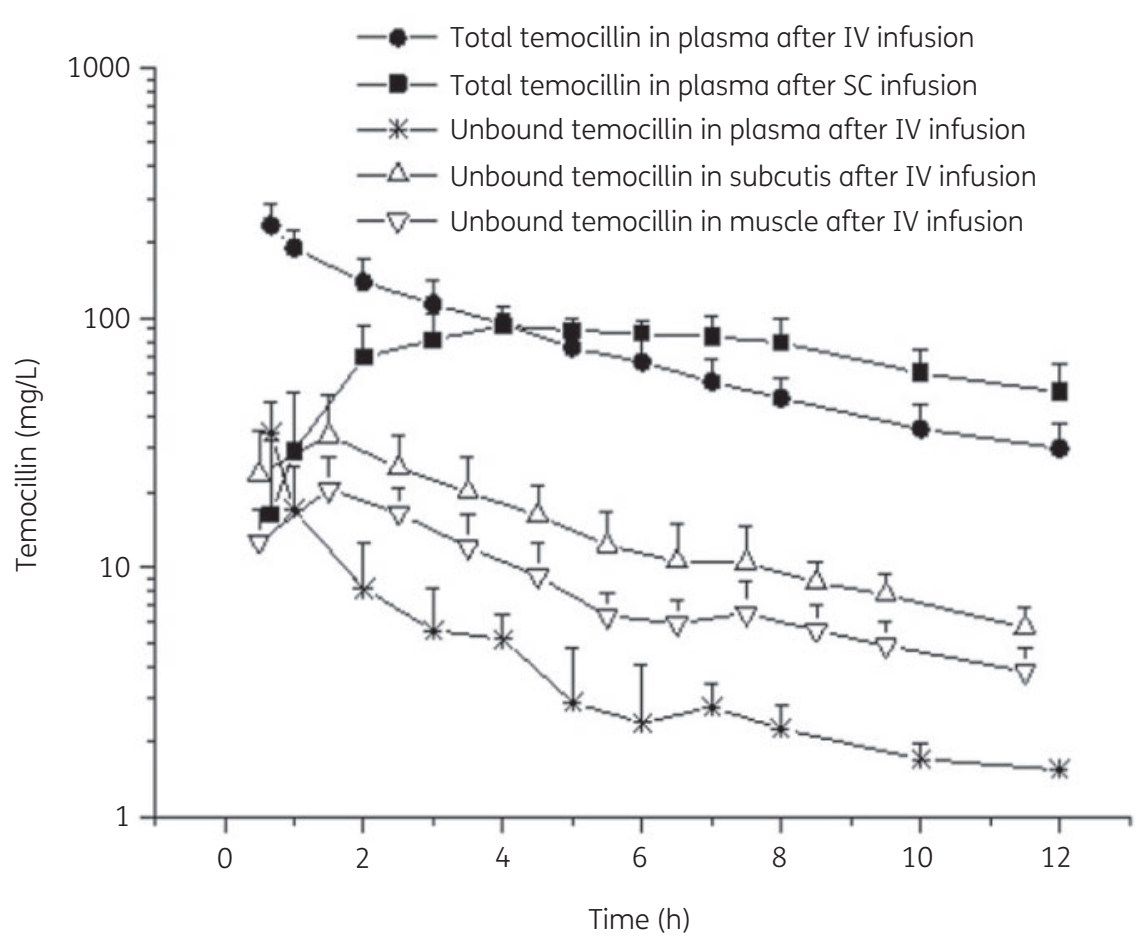

Figure 1. Concentration-time profiles of total temocillin in plasma of healthy volunteers after intravenous and subcutaneous infusion of $2 \mathrm{~g}$ of temocillin, and unbound temocillin in plasma, muscle and subcutaneous adipose tissue after intravenous infusion of $2 \mathrm{~g}$ of temocillin. Graphs show mean + SD.

Compared with plasma, peak concentrations were slightly delayed and were attained at $1.8 \pm 0.5 \mathrm{~h}$ post-dose. Both investigated soft tissues showed overall exposures to unbound temocillin markedly exceeding those in plasma. Subcutis showed a higher exposure than muscle, as denoted by a calculated unbound $\mathrm{AUC}_{0-12}$ of $173.4+53.1 \mathrm{mg} \cdot \mathrm{h} / \mathrm{L}$ compared with $105.7 \pm 29.6 \mathrm{mg} \cdot \mathrm{h} / \mathrm{L}$ in muscle.

\section{Discussion}

This study reports on the subcutaneous administration of temocillin and also describes the PK of unbound temocillin in plasma and soft tissues of healthy volunteers after intravenous infusion.

In contrast to intravenous dosing, which was tolerated very well, subcutaneous infusion showed some local tolerability issues. Five out of eight subjects (62.5\%) had at least one adverse event associated with subcutaneous infusion. These adverse events were mostly mild in intensity and limited to the time of infusion. The two local neurological side effects were most probably ascribable to mechanical lesions of peripheral nerves induced by the subcutaneously introduced infusion needle. The clinical context in which subcutaneous dosing might play a role has been framed earlier in this article. When evaluating patients who could qualify for this mode of administration, physicians will need to carefully weigh the risk of local discomfort against the potential practical advantages on the basis of an individual risk/benefit assessment. In order to mitigate local discomfort, local anaesthesia might be increased, e.g. by using a higher concentration of lidocaine in the subcutaneously administered temocillin solution.
In terms of PK, the concentration-time curves and key PK parameters of temocillin in plasma of healthy volunteers after intravenous infusion did not show relevant deviations from previous data. ${ }^{11,20,22}$ Subcutaneous administration achieved a very good overall exposure, as denoted by an $\mathrm{AUC}_{0-\infty}$ even higher than that observed after intravenous dosing. As a limitation in this context, it should be noted that $\mathrm{AUC}_{0-\infty}$ calculation was possible only with large extrapolated fractions, making the resulting relative bioavailability of $112 \%$ potentially prone to bias. This is due to the blood sampling scheme, which only covered $80 \%$ of the dosing interval. A PK sampling schedule encompassing the entire dosing interval might have been more appropriate. Still, it can be stated that this trial has demonstrated that the subcutaneous administration of temocillin is a feasible and pharmacokinetically valid way of dosing. Apart from this, the key information provided by this study in healthy volunteers is twofold: an unexpectedly high plasma protein binding and very good penetration into soft tissues, with unbound concentrations in muscle and subcutis exceeding unbound concentrations in plasma.

The $f_{u}$ of temocillin in plasma ranged from $15 \%$ to $4.9 \%$. On the one hand, this confirms the concentration-dependent nature of plasma protein binding of temocillin. ${ }^{11,20,23}$ On the other hand, it highlights a degree of plasma protein binding markedly above the previously assumed value of $85 \%$ for almost the entire concentration range observed in the present study in healthy volunteers. However, preliminary data from an in-depth analysis of temocillin's binding characteristics have already illustrated that the unbound fraction might be markedly higher in patients compared with healthy subjects, most likely due to 
Table 1. Key PK parameters of temocillin in investigated compartments

\begin{tabular}{|c|c|c|c|}
\hline & \multicolumn{3}{|c|}{ Total temocillin } \\
\hline & \multicolumn{2}{|c|}{ plasma } & \multirow[b]{2}{*}{$P$ value } \\
\hline & after intravenous dosing & after subcutaneous dosing & \\
\hline$C_{\max }(\mathrm{mg} / \mathrm{L})$ & $233.5 \pm 50.2$ & $100.0 \pm 15.5$ & $0.0001^{a}$ \\
\hline$T_{\max }(\mathrm{h})$ & $0.67 \pm 0.0$ & $4.8 \pm 2.0$ & $0.002^{a}$ \\
\hline$C_{12}$ & $29.9 \pm 7.4$ & $50.3 \pm 15.3$ & $0.002^{a}$ \\
\hline$A \cup C_{0-12}(\mathrm{mg} \cdot \mathrm{h} / \mathrm{L})$ & $959.4 \pm 185.0$ & $818.1 \pm 90.3$ & 0.02 \\
\hline$A \cup C_{0-\infty}(\mathrm{mg} \cdot \mathrm{h} / \mathrm{L})$ & $1197.1 \pm 276.6$ & $1314.0 \pm 242.1$ & \\
\hline$F(\%)$ & & $112 \pm 19$ & \\
\hline$V_{D}(\mathrm{~L} / \mathrm{kg})$ & $0.16 \pm 0.04$ & $0.18 \pm 0.03$ & 0.32 \\
\hline $\mathrm{CL}(\mathrm{L} / \mathrm{h})$ & $1.7 \pm 0.3$ & $1.6 \pm 0.3$ & 0.18 \\
\hline$t_{1 / 2}(h)$ & $5.3 \pm 1.3$ & $6.6 \pm 1.9$ & 0.14 \\
\hline
\end{tabular}

\begin{tabular}{|c|c|c|c|c|c|c|}
\hline & \multicolumn{3}{|c|}{ Unbound temocillin } & \multirow[b]{2}{*}{$P$ value $^{\mathrm{b}}$} & \multirow[b]{2}{*}{$P$ value $^{c}$} & \multirow[b]{2}{*}{ Pvalue ${ }^{\mathrm{d}}$} \\
\hline & plasma & muscle & subcutis & & & \\
\hline$C_{\max }(\mathrm{mg} / \mathrm{L})$ & $34.6 \pm 11.0$ & $20.6 \pm 6.8$ & $34.1 \pm 14.6$ & 0.09 & 0.036 & 0.889 \\
\hline$T_{\max }(\mathrm{h})$ & $0.67 \pm 0.0$ & $1.8 \pm 0.5$ & $1.8 \pm 0.5$ & 1.0 & 0.008 & 0.008 \\
\hline$C_{12}$ & $1.5 \pm 0.0$ & $3.8 \pm 0.9$ & $5.7 \pm 1.2$ & 0.012 & 0.012 & 0.012 \\
\hline $\mathrm{AUC}_{0-12}(\mathrm{mg} \cdot \mathrm{h} / \mathrm{L})$ & $67.2 \pm 13.3$ & $105.7 \pm 29.6$ & $173.4 \pm 53.1$ & 0.01 & 0.017 & 0.012 \\
\hline$V_{D}(\mathrm{~L} / \mathrm{kg})$ & $2.7 \pm 0.9$ & & & & & \\
\hline $\mathrm{CL}(\mathrm{L} / \mathrm{h})$ & $30.9 \pm 7.1$ & & & & & \\
\hline$t_{1 / 2}(h)$ & $5.0 \pm 1.1$ & & & & & \\
\hline
\end{tabular}

$F$, relative bioavailability [calculated as ( $A \cup C_{0-\infty}$ after subcutaneous dosing $/ A \cup C_{0-\infty}$ after intravenous dosing) $\times 100$ ].

Values shown are mean \pm SD.

${ }^{a}$ Statistically significant after correction for multiple testing.

${ }^{\mathrm{b}} \mathrm{P}$ value for muscle versus subcutis.

${ }^{c} P$ value for muscle versus unbound plasma.

${ }^{\mathrm{d}} P$ value for subcutis versus unbound plasma.

Table 2. $f T_{>\text {MIC }}$ values calculated for plasma, muscle and subcutis assuming a dosing scheme of $2 \mathrm{~g}$ temocillin twice daily

\begin{tabular}{lll}
\hline & \multicolumn{2}{c}{$f T_{>M I C}(\%)$} \\
\cline { 2 - 3 } Site & MIC $=8 \mathrm{mg} / \mathrm{L}$ & MIC $=16 \mathrm{mg} / \mathrm{L}$ \\
\hline Plasma & $18.4 \pm 5.2$ & $7.6 \pm 3.2$ \\
Muscle & $41.2 \pm 15.7$ & $13.9 \pm 12.8$ \\
Subcutis & $74.5 \pm 8.6$ & $34.5 \pm 18.5$ \\
\hline
\end{tabular}

Values shown are mean \pm SD.

hypoalbuminaemia and pharmacokinetic drug-drug interactions in the former population. ${ }^{23}$

Compared with low unbound drug concentrations in plasma, the microdialysis measurements in our study revealed surprisingly high drug levels in soft tissues. Importantly, it should be noted that relative recovery values determined during the calibration procedure of microdialysis probes were low but within the normal range and sufficient to allow reliable calculation of actual tissue concentrations. Unbound temocillin levels exceeding those in plasma have already been reported in bile and intraperitoneal fluid. ${ }^{20}$ High concentrations of unbound temocillin were also found in pancreatic tissue of a critically ill patient receiving temocillin as a continuous intravenous infusion. ${ }^{24}$

When trying to relate the mentioned measures of drug exposure to therapeutic efficacy, one must consider that many aspects of the PK/PD profile of temocillin are still fragmentary.

The $f T_{>\text {MIC }}$ was, as for other $\beta$-lactams, identified as the PK/PD index with the best correlation with temocillin efficacy. An fT $>$ MIC of $40 \%-50 \%$ was reported to be required for antibacterial effect and survival in animal infection models. ${ }^{20}$ However, the magnitude of $\mathrm{fT}_{>\mathrm{MIC}}$ required for optimal efficacy awaits more comprehensive definition.

Similarly, the available epidemiological data on temocillin susceptibility must be enriched for different geographical areas and different bacterial strains. According to recent reports, temocillin $\mathrm{MIC}_{90}$ values for relevant ESBL and AmpC producers range between 8 and $16 \mathrm{mg} / \mathrm{L}$, but the epidemiological cut-off (ECOFF) for key species has not been defined yet. . $^{2,21,25}$

As a result of these shortcomings, currently no EUCAST susceptibility breakpoints exist for temocillin. The definition of solid breakpoints and accordingly the issuing of widely accepted dosing recommendations will strongly depend on a more precise elucidation of the mentioned PK/PD aspects.

In the present study in healthy subjects, assuming an administration schedule of $2 \mathrm{~g}$ temocillin twice daily, $f T_{>\text {MIC }}$ values in 
plasma after intravenous infusion were $18.4 \%$ for an MIC of $8 \mathrm{mg} / \mathrm{L}$ and $7.6 \%$ for an MIC of $16 \mathrm{mg} / \mathrm{L}$. Both clearly fail to achieve the above-mentioned target of $40 \%-50 \%$. For the subcutaneous route, it is reasonable to expect even lower values from visual inspection of the concentration-time graph, although unbound concentrations were not explicitly measured after subcutaneous dosing. Of course, for the reasons mentioned above, these data are insufficient to draw clinical implications. Still, they underscore the urgency of an exhaustive characterization of temocillin's PK and PK/PD determinants in patients to either confirm or challenge the current dosing schedule of $2 \mathrm{~g}$ twice daily. Similarly, unless further data become available, it might be legitimate to explore more intensive administration schedules involving (i) higher doses, (ii) shorter dosing intervals or (iii) extended or continuous infusion.

Although PK/PD indices are generally developed and validated for plasma, we have computed $\mathrm{fT}_{>\text {MIC }}$ values also for soft tissues in order to estimate the activity of temocillin in these compartments. For the sake of mere comparison, they are compiled in Table 2 . According to these numbers, the dosing regimen evaluated in this study would offer sufficient exposure to cover infections with bacteria for which MICs are up to $8 \mathrm{mg} / \mathrm{L}$ in both soft tissues. The validity of using concentrations at the site of infection as a target should be explored further. For temocillin, the difference between unbound plasma concentrations and tissue concentrations is larger than has been described for other drugs and therefore may have a significant impact. Again, extrapolations from a healthy subject population to patients must be made only with caution, all the more since this single-dose study has suggested accumulation of temocillin in soft tissues but cannot depict steady-state conditions.

In particular, it should be kept in mind that the target population for temocillin, i.e. middle-aged to elderly patients often with a considerable burden of comorbidities, differs from our study population of young healthy males in a number of factors with potential impact on PK. Body composition changes with age, resulting in a relative increase in body fat and a decrease in total body water and lean body mass. Also, inter-individual variability in drug PK increases in older subjects, and the associated decline in renal function extends the half-life of renally excreted drugs, potentiating the risk of side effects and drug interactions. ${ }^{26}$ We nevertheless consider it legitimate to use this specific study population of healthy volunteers as a first step in generating new, previously unavailable data on a drug that might be increasingly important in clinical practice. Studies in healthy subjects offer the advantage of lower inter-individual variability, allowing even small sample sizes to yield homogeneous and thus meaningful PK data. Obviously, clinical studies in the target population are required to confirm the validity of temocillin as a treatment option in the elderly.

Furthermore, it should be noted that this trial measured unbound concentrations in plasma and tissue using two different methods: ultrafiltration and microdialysis, respectively. Ultrafiltration is a rapid and reliable in vitro method for the determination of protein binding. It is based on the centrifugationdriven passage of plasma water and free drug across a filter membrane into a reservoir where the unbound concentration can ultimately be quantified. Microdialysis offers the advantage of directly measuring free drug concentrations in a physiological environment in vivo. ${ }^{27}$
In summary, this study has revealed that subcutaneous administration of temocillin is feasible and results in sustained drug concentrations over time. Still, attention should be paid to the occurrence of local discomfort during subcutaneous infusion. Protein binding of temocillin was confirmed to be concentration dependent. The degree of plasma protein binding observed in this population of healthy volunteers was unexpectedly high compared with previous information and was in the range of 90\%$95 \%$ for the majority of evaluated timepoints. Importantly, the microdialysis measurements used in this study showed that unbound temocillin still penetrated well into muscle and subcutaneous adipose tissue. A full interpretation of the present dataset from a PK/PD perspective will require additional information from different patient populations. Meanwhile, with the description of soft tissue PK and of the subcutaneous route of administration, this study has contributed to the ongoing characterization of the PK/PD profile of temocillin and has indicated aspects that deserve to be further elucidated in a clinical setting.

\section{Acknowledgements}

This article is dedicated to the memory of Professor Dr Johan Willem Mouton.

\section{Funding}

This study was funded by EUMEDICA S.A., Belgium and by general functioning funding of the Pharmacologie cellulaire et moléculaire research unit, Université catholique de Louvain, Belgium.

\section{Transparency declarations}

S.V.D.V. is an employee of EUMEDICA SA. J.W.M. has received research funding from Adenium, Astrazeneca, Basilea, Cubist, Helberby, Nordic-Pharma, Polyphor, Roche, EUMEDICA, VenatorX, AiCuris, Gilead and Wockhardt. F.V.B. is research director from the Belgian Fonds de la recherche scientifique (FRS-FNRS). All other authors none to declare.

\section{References}

1 Livermore DM, Tulkens PM. Temocillin revived. J Antimicrob Chemother 2009; 63: 243-5.

2 Baghban A, Juthani-Mehta M. Antimicrobial use at the end of life. Infect Dis Clin North Am 2017; 31: 639-47.

3 Gallardo A, Gamboa FM. Feasibility of subcutaneous antibiotics for palliative care patients. Glob Drugs Ther 2017; 2: 1-5.

4 Champoux N, Du Souich P, Ravaoarinoro M et al. Single-dose pharmacokinetics of ampicillin and tobramycin administered by hypodermoclysis in young and older healthy volunteers. Br J Clin Pharmacol 1996; 42: 325-31.

5 Cree M, Stacey S, Graham N et al. Fosfomycin - investigation of a possible new route of administration of an old drug. A case study. J Cyst Fibros 2007; 6: 244-6.

6 Gauthier D, Schambach S, Crouzet J et al. Subcutaneous and intravenous ceftriaxone administration in patients more than 75 years of age. Med Mal Infect 2014; 44: 275-80.

7 Boon RJ, Beale AS. Studies with temocillin in a hamster model of antibioticassociated colitis. Antimicrob Agents Chemother 1985; 27: 980-1.

8 Frasca D, Marchand S, Petitpas F et al. Pharmacokinetics of ertapenem following intravenous and subcutaneous infusions in patients. Antimicrob Agents Chemother 2010; 54: 924-6. 
9 Barbot A, Venisse N, Rayeh F et al. Pharmacokinetics and pharmacodynamics of sequential intravenous and subcutaneous teicoplanin in critically ill patients without vasopressors. Intensive Care Med 2003; 29: 1528-34.

10 Walker P, Neuhauser MN, Tam VH et al. Subcutaneous administration of cefepime. J Pain Symptom Manage 2005; 30: 170-4.

11 EUMEDICA. 2014. Negaban SmPC. https://www.medicines.org.uk/emc/ product/466/smpc

12 Cockburn A, Mellows G, Jackson D et al. Temocillin. Summary of safety studies. Drugs 1985; 29 Suppl 5: 103-5.

13 De Vries-Hospers HG, Hofstra W, Welling GW et al. Influence of temocillin on colonisation resistance and consequences for therapy. Drugs 1985; 29 Suppl 5: 227-33.

14 European Medicines Agency. Guideline on the use of pharmacokinetics and pharmacodynamics in the development of antimicrobial medicinal products. 2016. https://www.ema.europa.eu/en/documents/scientific-guideline/ guideline-use-pharmacokinetics-pharmacodynamics-development-anti microbial-medicinal-products_en.pdf.

15 Mouton JW, Theuretzbacher U, Craig WA et al. Tissue concentrations: do we ever learn? J Antimicrob Chemother 2008; 61: 235-7.

16 Muller M. Science, medicine, and the future: microdialysis. BMJ 2002; 324: 588-91.

17 Chaurasia CS, Muller M, Bashaw ED et al. AAPS-FDA workshop white paper: microdialysis principles, application and regulatory perspectives. Pharm Res 2007; 24: 1014-25.

18 Ngougni Pokem P, Miranda Bastos AC, Tulkens PM et al. Validation of a HPLC-MS/MS assay for the determination of total and unbound concentration of temocillin in human serum. Clin Biochem 2015; 48: 542-5.
19 WinNonLin User's Guide. Certara, Princeton, NJ, USA. https://support.cer tara.com.

20 Alexandre K, Fantin B. Pharmacokinetics and pharmacodynamics of temocillin. Clin Pharmacokinet 2018; 57: 287-96.

21 Alexandre K, Reveillon-Istin M, Fabre R et al. Temocillin against Enterobacteriaceae isolates from community-acquired urinary tract infections: low rate of resistance and good accuracy of routine susceptibility testing methods. J Antimicrob Chemother 2018; 73: 1848-53.

22 Hampel B, Feike M, Koeppe P et al. Pharmacokinetics of temocillin in volunteers. Drugs 1985; 29 Suppl 5: 99-102.

23 Ngougni Pokem P, Matzneller P, Wulkersdorfer B et al. Protein binding of temocillin is lower in plasma from patients in intensive care units compared to healthy subjects: in vitro and in vivo studies. Poster presentation at the European Congress on Clinical Microbiology and Infectious Diseases (ECCMID), Madrid 2018. https://www.escmid.org/escmid_publications/esc mid_elibrary/material/?mid=62525.

24 Ngougni Pokem P, Capron A, Wallemaca P et al. Temocillin plasma and pancreatic tissue concentrations in a critically ill patient with septic shock. $J$ Antimicrob Chermother 2019; 74: 1459-61.

25 The European Committee on Antimicrobial Susceptibility Testing. http:// www.eucast.org.

26 Klotz U. Pharmacokinetics and drug metabolism in the elderly. Drug Metab Rev 2009; 41: 67-76.

27 Zeitlinger M, Derendorf H, Mouton JW et al. Protein binding: do we ever learn? Antimicrob Agents Chemother 2011; 55: 3067-74. 